\title{
Hierarchical Bayesian model for failure analysis of offshore wells during decommissioning and abandonment processes
}

\author{
Ahmed O. Babaleye ${ }^{a}$, Rafet Kurt ${ }^{\mathrm{a}}$, and Faisal Khan ${ }^{\mathrm{b},{ }^{*}}$ \\ aDepartment of Naval Architecture, Ocean and Marine Engineering, University of Strathclyde, \\ Glasgow, United Kingdom \\ ${ }^{\mathrm{b}}$ Centre for Risk, Integrity and Safety Engineering (C-RISE), Faculty of Engineering and \\ Applied Science, Memorial University of Newfoundland, St. John's, NL, Canada A1B 3X5 \\ *Correspondence author: fikhan@mun.ca
}

\begin{abstract}
Risk analysis of offshore wells decommissioning, and abandonment processes is challenging due to limited life-cycle information of the well, and failure data of safety barriers in place. To this end, it is essential to capture and implement the variability associated with the sparse data for conducting risk analysis with considerable confidence level. The hierarchical Bayesian analysis provides a viable alternative to address the uncertainty of the data through aggregation for each causation. Bayesian network, through its robust computation engine, is used to define dependence of causations and uses Bayes' theorem to update the analysis as new information becomes available. In addition, the Bayesian network helps to represent complex dependencies among causations through appropriate relaxation strategy to minimize uncertainty in the data, link parameter of interest, and overall accident scenario modelling. This paper presents the integration of Hierarchical Bayesian model with a Bayesian network to conduct the risk analysis of well decommissioning and abandonment processes. The proposed methodology is illustrated using a well plugging and abandonment operational failure reported by the Department of Mineral Management Service (MMS). The results demonstrate the potential of the proposed approach as a robust means to study complex well decommissioning activities.
\end{abstract}

Keywords: Bayesian networks; Hierarchical Bayesian model; failure analysis; well plugging and abandonment; decommissioning 


\section{Introduction}

Well plugging and abandonment ( $\mathrm{P} \& \mathrm{~A}$ ) operations are susceptible to unusual events as the reservoir conditions may evolve during or after the cessation of the production phase. The failure of these abandoned wells is driven by chemical, mechanical and physical causations (Kiran et al. 2017). The escape of hydrocarbon to the surface can be hazardous especially when an ignition source is present. Also, the formation fluids severity (sour or non-sour) can pose devastating threats with catastrophic consequence, in the event of a leak, making safety a major concern. These consequences may be exacerbated by the proximity of the P \& A platform to nearby properties and the environment. Generally, P \& A wells are expected to provide a permanent seal to a nonproducing wellbore such that no reason would warrant re-entering into the well. However, well barriers often fail for a variety of reasons, notably, degradation, cement shrinkage and noncompliance among others. The process of permanent $\mathrm{P} \& \mathrm{~A}$ aims at ensuring that a minimum of two cement plugs and a mechanical barrier (NORSOK D-010, 2013) are set at strategic intervals to contain possible migration of hydrocarbon uphole. These barriers tend to fail, although in no particular order, but one failure can trigger another in a complex interaction leading to consequent hydrocarbon leakage to the seabed. More recently, the Elgin well failure investigatory reports revealed that a "unique" corrosion event of the casings within the wellbore is the primary reason for the gas leak incident (Gergerechi et al. 2016; Total, 2013). To this end, various factors may weaken the barriers, and the reservoir conditions are difficult to ascertain during cessation of the production phase. Also, inspection data kept by oil and gas operators are often either, incomplete or lacking relevant sections due to change management, making the available data for safety analysis sparse. This sparsity of data, due to limited experience and knowledge of the overall uncertainty, are obtained from different sources such as experts' opinions and analogous information from similar activities. Therefore, a sophisticated risk analysis approach capable of 
quantifying and managing these uncertainties through convergence is required to provide a considerable level of confidence before and during the P \& A operation. Many authors have developed and proposed a variety of methods to overcome the uncertain and scattered data concerns. For example, Lavasani et al. (2015) utilised the fuzzy set and possibility theory through fault tree analysis to quantify leakage risk in abandoned oil and natural-gas wells. Schobi et al. (2016) proposed a sampling technique using polynomial-chaos kriging to estimate the failure probability of rare events. A hybrid framework based on importance splitting method was also proposed for quantifying rare event failure probability (Chakraborty et al., 2017). Monte-Carlo simulation and surrogate models in composite systems have also been investigated (Li et al., 2011; Hua et al. 2015). Although efforts have been made to provide efficient frameworks for estimating complex events' failure probability, however, the accuracy of these methods often depend on the assumptions made on model formulation and parameter accuracy. Babaleye et al. (2019b) proposed a model to handle the evolving conditions of the well barriers, their failure dependencies and uncertainty in the data. The model uses advanced logic conditions such as Noisy-OR and leaky Noisy-OR to define the conditions and data dependency. However, this model incorporated unrefined data in its analysis and relied on Bayesian networks (BN) robust engine to handle uncertainties associated with the data, paving the way for a more advanced approach. More recently, hierarchical Bayesian analysis (HBA) have been adopted due to its capabilities in aggregating source-to-source data in a systematic manner with underlying assumptions that scale and shape parameters are functions of distributions of interest (Babaleye and Kurt, 2019a; Arzaghi et al., 2018; El-Gheriani et al., 2017a; El-Gheriani et al., 2017b; Yang et al., 2013; Yan et al., 2010; Siu et al., 1998). In this literature, forms of HBA have been trained with accident precursor data (APD) sourced from locations of varying legislation, well types and operations, geological and 
environmental conditions. These analogous data further introduce uncertainty to the accident analysis.

Well P \& A, like many other complex engineering systems, is characterized by a high level of uncertainty. This uncertainty, involving an increased number of formation fluids-barriers mechanisms and their interacting dependencies, require a robust probabilistic risk analysis tool like BNs. Moreover, the safety analysis of an offshore well undergoing P\&A operation, requires accurate knowledge of all the variables and their impacts and failure data. Therefore, it is essential to model the inherent risks, in its entirety adequately, only then can the overall risk plan be complete, comprehensive and effective. It is to be noted that BNs are limited in their ability to accurately elicit the uncertainty between causations and their effects, in the form of conditional probability tables (CPT). Typically, these interactions are often modelled as though all causations are influencing the effects. In practice, this need not be true as parameters may be over- or underdefined. In the context of well P \& A, it is necessary to model these parameters accurately to make the risk analysis realistic, as these CPT parameters often rely on expert judgements or literature during the decommissioning planning phase.

Based on the foregoing, the present study aims at developing a comprehensive data collection and failure analysis formalism for an offshore oil and gas well subject to ongoing decommissioning and abandonment operation. The formalism relies on the integration of hierarchichal Bayesian analysis and Bayesian network model to conduct and assess the risks inherent in the causations of a well P\&A operational failure. Dependency among interacting causations established based on a joint probability distribution and elicitation of an advanced logic gate within the CPTs, which has not been addressed in the offshore decommissioning risk analysis context thus far. This methodology can comprehensively conduct a probabilistic risk analysis, considering the effect of new evidence to update probabilities, and validate developed model through sensitivity and 
diagnostic analysis to assess potential fire and explosion in the event of hydrocarbon release. Consequently, preventing losses and ensuring safety.

The rest of the study is organized as follows: The proposed integrated hierarchical Bayesian analysis and Bayesian networks model with advanced logic are briefly discussed in Section 2. Section 3 illustrates the case study and the application of the proposed methodology. Section 4 offers the conclusion and future research evolving from this study.

\section{The Proposed Methodology}

It has been established that failure data of offshore wells under decommissioning are often sparse, and where there are such data, it is usually incomplete or non-absolute through similar operation from historical experience. To address this concern, it is imperative to develop a framework capable of aggregating the data to a considerable extent that it can completely represent the problem under study. The proposed framework is based on the incorporation of HBA with BN modelled through advanced logic to estimate causation events' failure probabilities, re-assess the occurrence of a critical event characterized by leakage of formation fluids to the surface and, handle the issues of parameters uncertainty, respectively. The proposed framework is as illustrated in Fig. 1. 


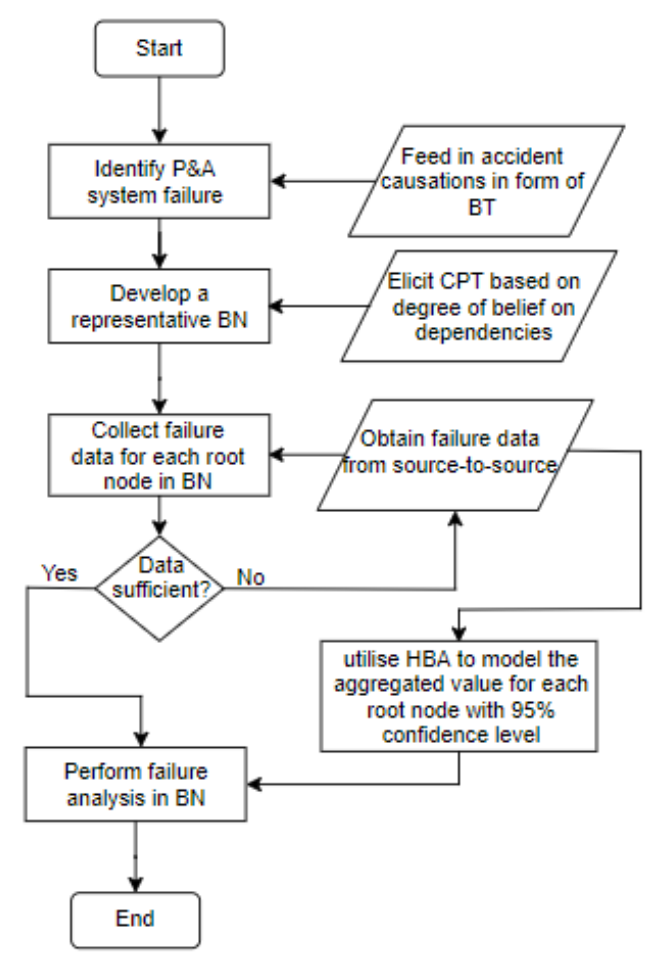

Figure 1. Proposed method algorithm

\subsection{Accident scenario Modelling}

The Minerals Management Service (MMS, 2000) reported the accident evolution during well P\&A operations and identified the regions of potential compromise within the wellbore to be a leak through the zone isolation plugs, the lower plug and the upper plug. The safety-critical event defined in the report (i.e. leakage through mudline) is adopted as the pivot event within the BT. This present study focuses on the strategic leakage pathways within the wellbore during the offshore well abandonment operation and extends the identified paths to include dependencies among causations.

\subsection{Hierarchical Bayesian Modelling}

Following the BT construction, each causation event probability must be estimated using HBA. The data obtained for each event is often a guestimate according to risk assessor's degree of belief or judgements and are typically subjective due to the different knowledge of the process. Guestimates are not accurate and may take the form of possibilities, probabilities or failure rates. 
Therefore, it is only practical to aggregate them systematically. HBA has a robust computation engine capable of handling bulk and divergent set of aggregated data (Lund et al., 2009). One crucial challenge during the HBA process is the credibility of assumptions relating to the precision of selected prior distribution function. The HBA model utilises a multi-level prior distribution function and can be impractical to solve numerically, especially, when the conjugate pairs have different distributions (Ferson et al., 2005). This study utilises gamma-function due to its similar conjugate properties to address this concern. The HBA as a statistical tool is employed to estimate the parameters of prior and posterior distributions in multiple stages modelled through the Bayesian method as highlighted in the following steps: likelihood functions definition, estimation of the informative priors and hyper-prior parameters, accordingly, with assumed mean and variance for the distribution function.

\subsubsection{Defining likelihood function}

In this first step, the likelihood function is defined concerning a specified parameter for a set of data emanating from the different source. This likelihood function, obtained through averaging of the specified parameter over all values within the parameter group, can be expressed as in Eq. (1).

$$
f(x \mid \alpha, \beta)=\int f(x \mid \psi) \cdot f_{o}(\psi \mid \alpha, \beta) d \psi
$$

With the adoption of gamma distribution on the specified parameter to confine the prior and posterior distributions as conjugate pair, the informative prior distribution and its corresponding hyper-prior parameters defined by a non-informative distribution can be incorporated to obtain the updated (posterior) second stage prior, given by the two-dimensional form of Bayes' theorem, thus;

$$
f_{1}(\alpha, \beta \mid x)=\frac{f_{0}(\alpha, \beta) \cdot f(x \mid \alpha, \beta)}{\iint f_{0}(\alpha, \beta) \cdot f(x \mid \alpha, \beta) d \alpha d \beta}
$$


To obtain the predictive posterior distribution, the first stage prior distribution is updated through instantiating the posterior of the hyper-prior parameters. The resulting predictive posterior distribution - termed the population variability curve (PVC) - can be obtained by Eq. (3) which can further be feed into the model as an informative prior distribution when non-absolute safety data is observed during case-specific trials as expressed in Eqs. (4) and (5).

$$
\begin{aligned}
& f_{1}(\psi \mid x)=\iint f_{0}(\psi \mid \alpha, \beta) \cdot f_{1}(\alpha, \beta \mid x) d \alpha \mathrm{d} \beta \\
& f_{1}\left(\psi \mid x^{-}, x\right)=\frac{f_{1}(\psi \mid x) L\left(x^{-} \mid \psi\right)}{\int f_{1}(\psi \mid x) L\left(x^{-} \mid \psi\right) d \psi} \\
& f_{1}\left(\psi \mid x^{-}, x\right) \propto f_{1}(\psi \mid x) L\left(x^{-} \mid \psi\right)
\end{aligned}
$$

Where $f_{1}\left(\psi \mid x^{-}, x\right)=$ the updated posterior distribution with case-specific trials

$\int f_{1}(\psi \mid x) L\left(x^{-} \mid \psi\right) d \psi=$ the likelihood function for case-specific trials

$f_{1}(\psi \mid x)=$ the predictive posterior distribution

$f_{1}(\alpha, \beta \mid x)=$ the posterior of the hyper-prior parameters

$\alpha, \beta=$ the shape and scale parameters, respectively (hyper-prior parameters)

$f_{0}(\psi \mid \alpha, \beta)=$ the first stage prior distribution for the data set

$f(x \mid \alpha, \beta)=$ the likelihood function of the hyper-prior parameters

$f_{0}(\alpha, \beta)=$ the second stage prior or hyper-prior distribution

$\psi=$ the parameter under consideration (failure rate or probability)

$x, x^{-}=$the prior and posterior datasets

The distributions of the hyper-prior parameters $\alpha$ and $\beta$ are assumed to have a gamma distribution with mean and variance $\left(\mu_{\mathrm{x}}=\alpha \beta, \sigma_{\mathrm{x}}^{2}=\alpha \beta^{2}\right)$ equal to $1.00 \mathrm{e}-4$.

\subsubsection{Estimating failure probability}

Occurrence probability or failure rates are often required to conduct a probabilistic risk analysis. In the case of offshore decommissioning activities, such parameters are obtained from similar activities, historical data or accident precursor data. Several unrelated data are sometimes modelled using probability density functions (PDFs) based on the source-to-source variability techniques (Kelly and Smith, 2011; Yan and Haimes, 2010; Kelly and Smith, 2009) and prior knowledge of similar data - e.g. process, mining, aerospace and nuclear industries. One form of analyzing the 
PDFs is to distribute a set of data indicating the frequency of successes $x_{i}$ observed over $N_{i}$ trials with Binomial properties such that;

$$
P_{f}\left(x_{i} \mid P\right)=\left(\begin{array}{c}
N_{i} \\
x_{i}
\end{array}\right) P^{x_{i}} \bar{P}^{\left(N_{i}-x_{i}\right)}, \quad 0 \leq x_{i} \leq N_{i}
$$

The first stage prior distribution for the data set obtained from Eq. (6) gives;

$$
f_{0}(P \mid \alpha, \beta)=\frac{\Gamma(\alpha+\beta)}{\Gamma(\alpha) \Gamma(\beta)} P^{(\alpha-1)} \bar{P}^{(\beta-1)}
$$

In the case where discrete data representing the failure, $x$ is presented in the form of failure rate, $\lambda$ and exposure time, $t$, then the likelihood function follows a Poisson distribution given by Eq. (8).

$$
L\left(x_{i} \mid \lambda_{\mathrm{i}}\right)=\frac{\left(\lambda_{i} t\right)^{x_{i}} e^{-\lambda_{i} t}}{x_{i} !}, \quad i=0,1, \ldots
$$

The corresponding first stage prior distribution for the data set yields Eq. (9).

$$
f_{0}(\lambda \mid \alpha, \beta)=\frac{\beta^{\alpha} \lambda^{\alpha-1} e^{\beta \lambda}}{\Gamma(\alpha)}
$$

\subsubsection{Modelling syntax in MATLAB}

In the abundance of data obtained from a variety of sources, the most common method of processing such data has been through averaging. However, this averaging method often leads to inconsistencies in the results. Therefore, it is necessary to distribute this data set using the HBA formalism by adopting the sampling method that can yield structured data sets from the posterior predictive distribution as follows;

$$
\begin{gathered}
x_{i} \sim \operatorname{bin}\left(P_{i}, N_{i}\right) \\
P_{i} \sim \operatorname{beta}(\alpha, \beta) \\
\alpha \sim \operatorname{gamma}\left(\mu_{x}, \sigma_{x}^{2}\right) \\
\beta \sim \operatorname{gamma}\left(\mu_{x}, \sigma_{x}^{2}\right)
\end{gathered}
$$


In this paper, the gamma distribution model is coded in MATLAB (R2018a), taking advantage of its in-built gamma pdf tools (Fig 2). The aggregation procedure within HBA enables the failure probabilities to be obtained as a mean value with a $95 \%$ confidence interval.

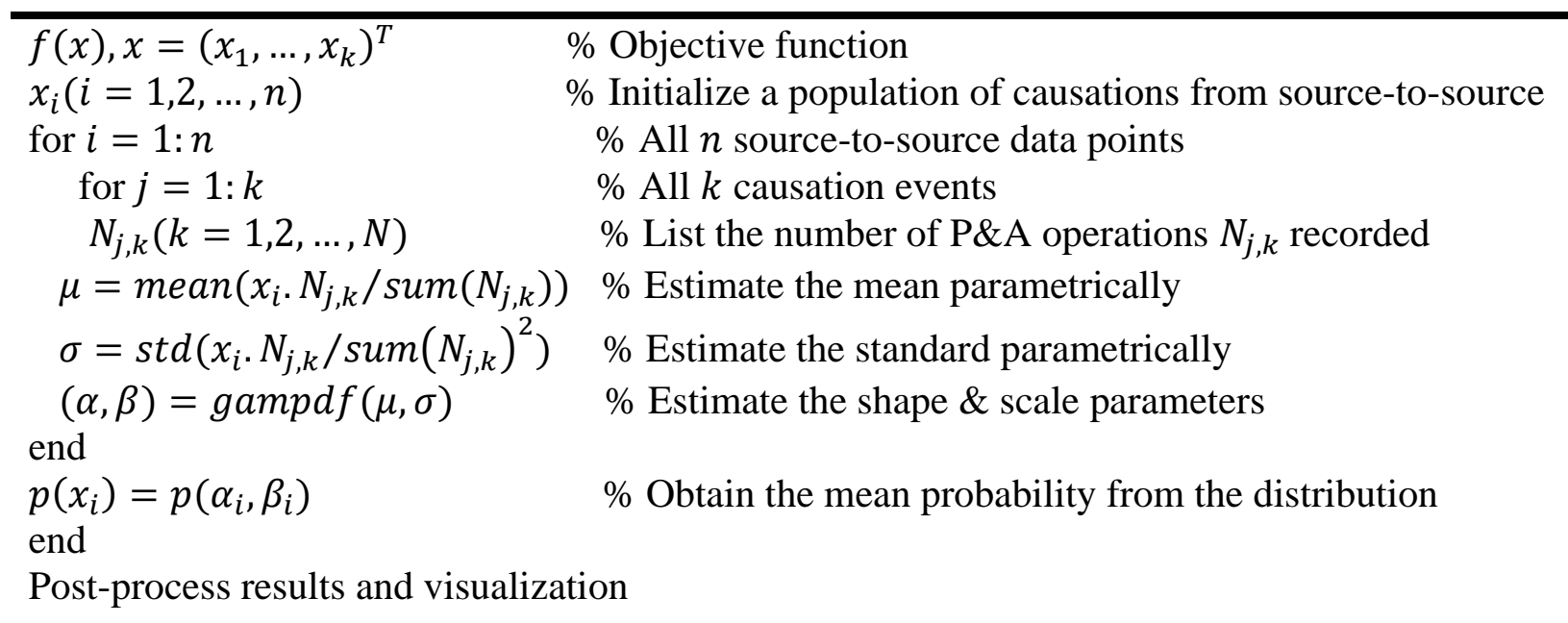

Figure 2. MATLAB code for probability estimation

\subsection{Quantitative failure modelling}

Following the accident scenario analysis conducted in section 2.1 and the prior probability estimation discussed in section 2.2.2, it would be necessary to construct a bowtie to depict the accident root causes and its evolution. The bowtie, consisting of fault tree on the right side and event tree on its left side, can represent the accident evolution in its entirety. However, the bowtie cannot handle real-time analysis unless it is coupled with advanced techniques. This is because of its fault tree and event tree constituents whose computation assumes that each root cause is statistically independent, which need not be true. Therefore, to conduct dynamic failure analysis, the bowtie must be mapped into a Bayesian network $(\mathrm{BN})$ as shall be briefly discussed in section

\subsection{1.}

\subsubsection{BT to BN Mapping procedure}

The mapping procedure involves converting each root cause, intermediate events and the top event of the fault tree into the root nodes, intermediate nodes and pivot node of the BN. Also, the safety 
barriers events and consequence events of the event tree are converted into the safety nodes and a leaf node(s), respectively. More detail about the mapping algorithm can be found in the literature (Khakzad et al., 2013a; Baddredine and Ben Amor, 2010)

\subsubsection{BN modelling}

BNs are directed acyclic graphs (DAG) use to analyze complex interactions and conditional dependencies among events under uncertainty. The events are represented as nodes with associated conditional probability distributions (Nielsen and Jensen, 2009; Onisko et al., 2001). Each node of a BN denotes a discrete random variable and directed arcs linking the nodes reflect the logical dependencies among causations. Considering Fig. 3, with discrete variable, $A_{i}=A_{1}, \ldots, A_{n}$ the joint probability distribution follows the product rule given by Eq. (10).

$$
P\left(A_{1}, \ldots, A_{n}\right)=\prod_{i=1}^{n} P\left(A_{i} \mid P_{a}\left(A_{i}\right)\right)
$$

Where $P_{a}\left(A_{i}\right)$ and $P\left(A_{i} \mid P_{a}\left(A_{i}\right)\right)$ are the parent node and CPT of $A_{i}$, respectively. In the presence of new evidence, knowledge or observation $\varepsilon$, Eq. (10) can be reformed to estimate the posterior probability distribution in the form of Bayes' theorem;

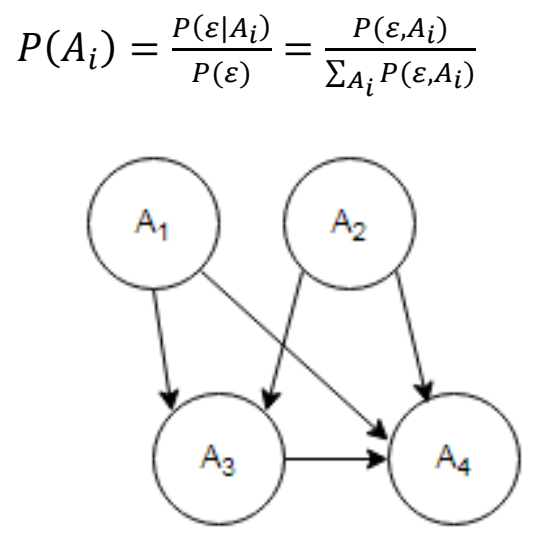

Figure 3. Typical BN structure.

Further expansion of Eq. (10) yields Eq. (12) as follows.

$$
P\left(a_{1}, \ldots, a_{4}\right)=P\left(a_{4} \mid a_{3}, a_{2}, a_{1}\right) \cdot P\left(a_{3} \mid a_{2}, a_{1}\right) \cdot P\left(a_{2}\right) \cdot P\left(a_{1}\right)
$$


Where $a_{1}, \ldots, a_{4}$ are the occurrence outcomes of variables $A_{1}, \ldots, A_{4}$, respectively. It is worth mentioning that Eq. (11) can be used to perform consequence probability updating when new information about an event of interest is observed. It can also be used for sequential updating (also called probability adapting) when evidence of a consequence is given.

\subsection{Uncertainty modelling}

\subsubsection{Uncaptured data uncertainty modelling}

Many relaxation strategies exist for modelling uncertainty. Notably, leaky noisy-OR (LN-OR) gates have been developed and demonstrated to account for the accidents initiated by uncaptured hazards (Antonucci, 2011). The LN-OR formalism is especially, applicable to a plugging and abandonment operation where reservoir conditions, the age of the well, mechanical, physical and chemical damages within the casings of the wellbore are all variables of uncertainty and could be more. As shown in Fig. 3, the accident contribution from each node $A_{1}, A_{2}$ and $A_{3}$ is assumed to be independently capable of leading to the consequence node $A_{4}$ when other root nodes are absent. In practice, this need not be true, as there are uncaptured hazardous events not represented in the model that can cause the failure of the system. These uncaptured events are accounted for by introducing an additional parameter l 'leaky probability', such that $0 \leq l_{o}<1$. The leak probability assumes that the occurrence of uncaptured events will adequately provide new knowledge of the consequence event by incorporating another causal variable $L$, with a 'link probability', given by $l_{o}=P_{i}$. It is to be noted that this additional parameter, albeit efficient, does not consider the uncertainty associated with leak probability, link probability and the outcomes of the parent variables in the accident model (Babaleye et al., 2019). These uncertainties can be modelled using data uncertainty modelling formalism.

\subsubsection{Data and parameters uncertainty modelling}


An extension of the LN-OR - imprecise noisy-OR (ILN-OR) - is introduced to account for the uncertainty associated with elicitation parameters and unknown condition of the reservoir leading to inaccurate failure data state variables estimations in the risk model (Fallet-Fidry et al., 2012). The ILN-OR assumes that occurrence and non-occurrence representation of state variables are not sufficient due to the probability that the state variable may or may not exist. For the sake of simplicity, the leaky probability, and corresponding link probability are assigned a lower and upper bound, such that $l_{\min } \leq l_{o}<l_{\max }$ and $P_{i, \min } \leq P_{i}<P_{i, \max }$. Such assignments will enable the state variables to be represented as either being true, false or true-false simultaneously. This is primarily a practical way to obtain failure probabilities in intervals rather than discrete values, to provide the risk assessor enough information to develop a conservative safety mechanism. Thus, an extended CPT for the accident model is given by.

$$
\begin{gathered}
\mathrm{P}\left(\mathrm{A}_{\mathrm{i}}=\left\{\mathrm{a}_{\mathrm{i}}\right\} \mid \mathrm{A}_{\mathrm{j}, \mathrm{j} \neq \mathrm{i}}\right)=1-\left[\left(1-l_{\text {min }}\right) \prod_{\mathrm{i}: \mathrm{l}_{\mathrm{j}} \in \mathrm{A}_{\mathrm{j}}}\left(1-\mathrm{P}_{\mathrm{i}, \min }\right)\right] \\
\left.\mathrm{P}\left(\mathrm{A}_{\mathrm{i}}=\left\{\overline{\mathrm{a}}_{\mathrm{i}}\right\} \mid \mathrm{A}_{\mathrm{j}, \mathrm{j} \neq \mathrm{i}}\right)=\left[\left(1-l_{\text {max }}\right) \prod_{\mathrm{i}: \mathrm{l}_{\mathrm{j}} \in \mathrm{A}_{\mathrm{j}}}\left(1-\mathrm{P}_{\mathrm{i}, \max }\right) \cdot \prod_{\mathrm{i}: \mathrm{l}_{\mathrm{j}} \in \mathrm{A}_{\mathrm{ij}}}\left(1-\mathrm{P}_{\mathrm{i}, \max }\right)\right]\right] \\
\mathrm{P}\left(\mathrm{A}_{\mathrm{i}}=\left\{\mathrm{a}_{\mathrm{i}}, \overline{\mathrm{a}}_{\mathrm{i}}\right\} \mid \mathrm{A}_{j, j \neq i}\right)=\left[\left(1-l_{\text {min }}\right) \prod_{i: l_{\mathrm{j}} \in \mathrm{A}_{\mathrm{j}}}\left(1-\mathrm{P}_{\mathrm{i}, \min }\right)\right]-(1- \\
\left.\left.\left.l_{\text {max }}\right) \prod_{i: l_{\mathrm{j}} \in \mathrm{A}_{\mathrm{j}}}\left(1-\mathrm{P}_{\mathrm{i}, \max }\right) \cdot \prod_{i: l_{\mathrm{j}} \in \mathrm{A}_{\mathrm{ij}}}\left(1-\mathrm{P}_{\mathrm{i}, \max }\right)\right]\right]
\end{gathered}
$$

Eqs. (13), (14) and (15) enable the states of both parent and child nodes to be specified with more than binary states. To incorporate the uncertainty of the states of the parent variables, $a_{3}, \bar{a}_{3}$ a modality probability $x$ is assigned. For example, the CPT of $A_{3}$ given the causations $A_{1}$ and $A_{2}$ is as presented in Table 1 , where $\mathrm{P}_{\mathrm{i}, \min }$ is assumed to be equal to $\mathrm{P}_{\mathrm{i}, \max }$ and $l_{\mathrm{o}}=l_{\min }=l_{\max }$. 
Table 1. Imprecise leaky noisy-OR CPT for node $A_{3}$

\begin{tabular}{|c|c|c|c|c|c|c|c|c|c|}
\hline$A_{1}$ & \multicolumn{3}{|c|}{$a_{1}$} & \multicolumn{3}{|c|}{$\bar{a}_{1}$} & \multicolumn{3}{|c|}{$a_{1}, \bar{a}_{1}$} \\
\hline$A_{2}$ & $a_{2}$ & $\bar{a}_{2}$ & $a_{2}, \bar{a}_{2}$ & $a_{2}$ & $\bar{a}_{2}$ & $a_{2}, \bar{a}_{2}$ & $a_{2}$ & $\overline{a_{2}}$ & $a_{2}, \bar{a}_{2}$ \\
\hline$a_{3}$ & $\mathrm{p}_{1} \mathrm{p}_{2}$ & $\mathrm{p}_{1}$ & $x \mathrm{p}_{1}$ & $\mathrm{p}_{2}$ & $l_{\mathrm{o}}$ & $x l_{\mathrm{o}}$ & $x \mathrm{p}_{2}$ & $x l_{o}$ & $x^{2} l_{0}$ \\
\hline $\bar{a}_{3}$ & $\left(1-\mathrm{p}_{1}\right)\left(1-\mathrm{p}_{2}\right)$ & $1-\mathrm{p}_{1}$ & $1-x \mathrm{p}_{1}$ & $1-\mathrm{p}_{2}$ & 1 & $x$ & $1-x p_{2}$ & $x$ & $x^{2}$ \\
\hline$a_{3}, \bar{a}_{3}$ & $\mathrm{p}_{2}+\mathrm{p}_{1}-1$ & $2 p_{1}-1$ & $\begin{array}{l}2 x \mathrm{p}_{1} \\
-1 \\
\end{array}$ & $2 p_{2}-1$ & $l_{o}$ & $\begin{array}{l}x\left(l_{0}\right. \\
-1)\end{array}$ & $2 x \mathrm{p}_{2}-1$ & $x\left(l_{\mathrm{o}}-1\right)$ & $x^{2}\left(l_{\mathrm{o}}-1\right)$ \\
\hline
\end{tabular}

\section{Application of Methodology}

The plugging and abandonment of offshore oil and gas wells is one of many rare events where accidents can escalate rapidly if the operational hazards are not captured wholly and carefully.

\subsection{Step 1: Leakage Scenario Modelling}

The problem formulation for the leak route of hydrocarbon within the offshore well during permanent abandonment operation (Fig. 4) is identified through visual inspection of the design schematics. The presence of pressure differentials between the production zone and the hydrostatic pressure or injection into other nearby wells, a build-up of pressure over a prolonged time can develop, leading to over-pressurization of fluid. The pressurized fluid within the production zone tends to migrate over the zone isolating barrier $\left(\mathrm{B}_{1}\right)$ and the primary well barrier $\left(\mathrm{B}_{2}\right)$ placed at the casing closest to the production zone. The ingress of formation fluid to the surface casing where there is a secondary well barrier further exacerbate the failure. Formation fluids then migrate uphole to the mudline if the stopped/balanced plug or secondary well barrier $\left(\mathrm{B}_{3}\right)$ fails. The secondary well barrier is compromised due to surface casing corrosion caused by prolonged exposure of the migrating fluid or yielding of the casing due to internal loadings within the well such as formation loads or geological forces. The potential compromise of the secondary well barrier leads to the leakage of formation fluid through the surface casing $\left(\mathrm{B}_{4}\right)$. The leak then deviates uphole and continue to the mudline through the hanger and/or seal assembly (B5) due to the presence of a path caused by de-bonding or annulus barrier degradation between the surface 
and production casing. The leak then migrates freely toward the conductor casing $\left(\mathrm{B}_{6}\right)$, following the failure of the secondary well barrier to provide containment. The migration towards the conductor casing is similarly a deviation uphole caused by insufficient barrier length in annulus or degradation of the annulus barrier. The insufficient barrier length is because of slippage due to inadequate barrier density or loss of barrier, thus, preventing the barrier from performing intended squeeze job. The migrating fluid can, at this point leak freely within the annulus to the conductor hanger assembly (B7). The leak through the hanger assembly is especially due to the contamination and degradation of the annulus barrier. The contamination arises from poor mud and filter cake removals, which leave a pathway for formation fluid to flow uphole, or, potential shrinkage of the barrier. Due to the subjective modelling of these leak routes, it is necessary to ensure that the results can be validated and applicable to all types of wells and locations with different geological formations. Therefore, this present work adopts the imprecise leaky noisy-OR model to address overall uncertainty - from the quantification of dependencies to reservoir conditions - in the analysis.

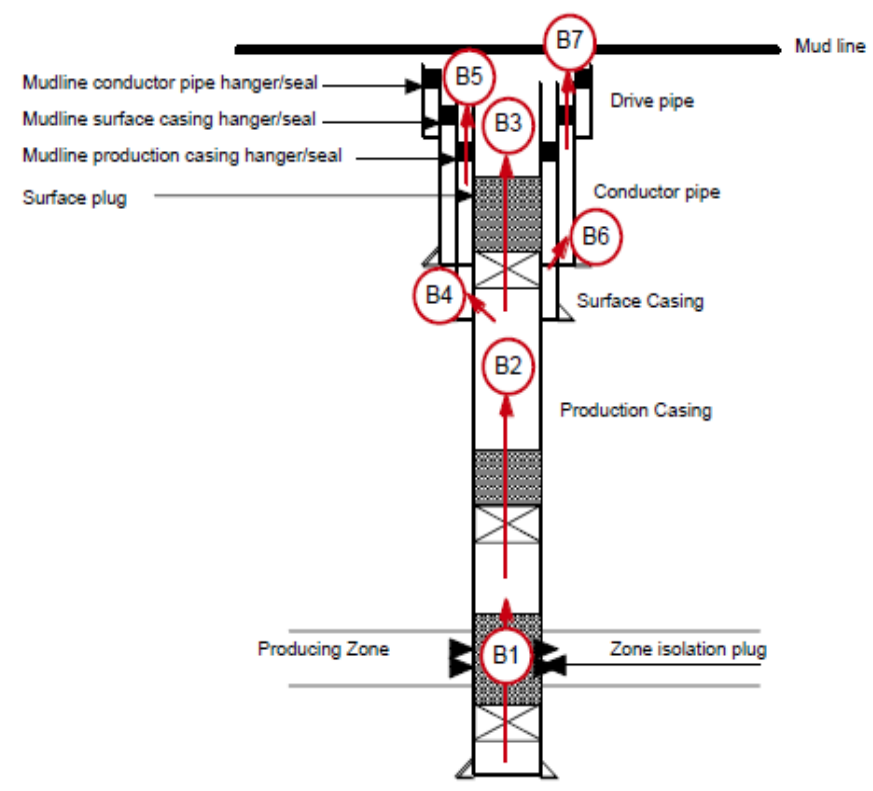

Figure 4. Permanent well plug and abandonment leak route (MMS, 2000).

\subsection{Step 2: Consequence Modelling}


This paper aims to examine the devastating accidents emanating from the release of hydrocarbon in an abandoned well subject to data sparsity. Typically, these accidents are characterized by the decommissioning personnel safety, environmental safety, loss of asset regarding fire and explosion. Personnel safety is accounted for by the loss of personnel's life during the plugging operation due to fire, explosion and suffocation. The environmental risk is defined by the amount of hydrocarbon spill and its adverse effect on marine lives, nearby residents, potential property damage and the cost of remediation. The loss of asset is attributed to the potential loss of the rig used for the abandonment operation. Fire and explosion are the main threat given the scenario that hydrocarbon has leaked uphole to mudline. The evolution of a catastrophe is assumed to emanate from the point where a leak exists, and this study assumes the well contained non-sour formation fluids. The leak propagates to the formation of fire or hazardous cloud until it is escalated through an ignition source. For a gas well, a jet fire (or pool fire for a liquid well) propagates. A vapor cloud is formed in the absence of an ignition source and may be escalated by the wind. The consequence of such leak from $\mathrm{C}_{1}$ to $\mathrm{C}_{6}$ is shown in Table 3 and their occurrence sequence represented on the event tree constituents of Fig. 5.

To prevent the occurrence of these consequences, five safety barriers have been identified such as hydrocarbon detection sensor (HDS), ignition prevention system (IPS), flame arrestor system (FAS), alarm and sprinkler (AaS), and emergency evacuation system (EES) as presented in Table 4. The hydrocarbon detection sensor is a barrier designed to notify monitoring personnel if there has been polarity difference between water at mudline and leaked hydrocarbon. It prevents the occurrence of hydrocarbon release uphole to the surrounding water. The failure of the HDS activates the IPS, which controls the escalation of vapor cloud into pool fire in the likely event of fire and explosion. The reliability of the ignition prevention system is an essential factor in the occurrence of catastrophe, as fire cannot ensue without the ignition barrier prior failure. The FAS 
is immediately relied on to disconnect the combustion elements (temperature, oxygen and hydrocarbon), soon as fire and explosion events occur. The failure of the FAS escalated fire, loss of the offshore asset and nearby properties including casualties, necessitating the installation of an AaS system to consolidate the potential for fire and explosion. The EES reduces the extent of damage caused by fire and explosion due to the consequent failure of preceding safety barriers. The timing of the AaS to function is hugely important in this scenario; otherwise, the emergency evacuation plan might be insignificant following a catastrophe. The failure of the emergency evacuation plan leads to significant damage to offshore assets and nearby properties including fatalities.

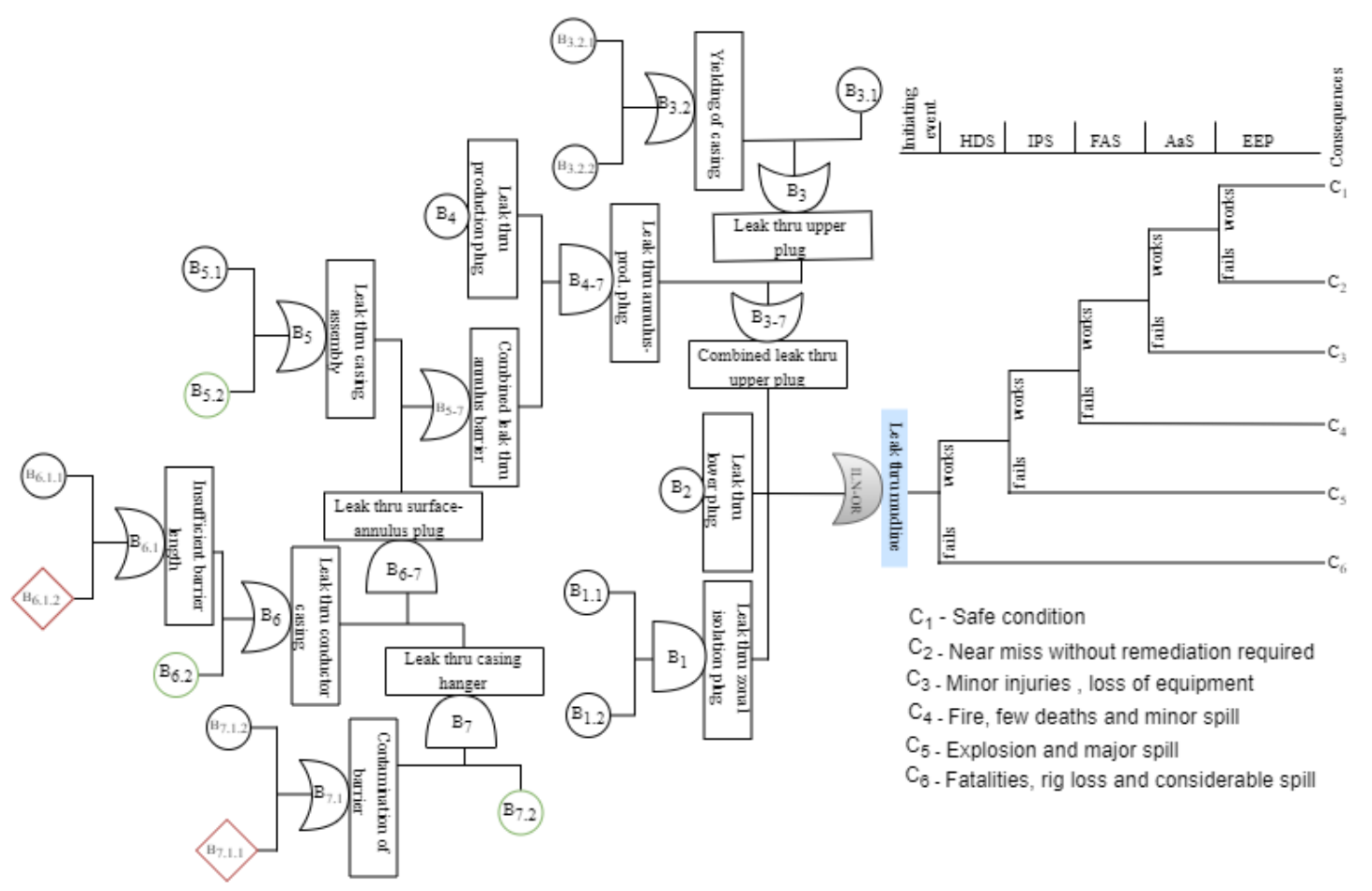

Figure 5. BT model representing failure during abandonment operation. 


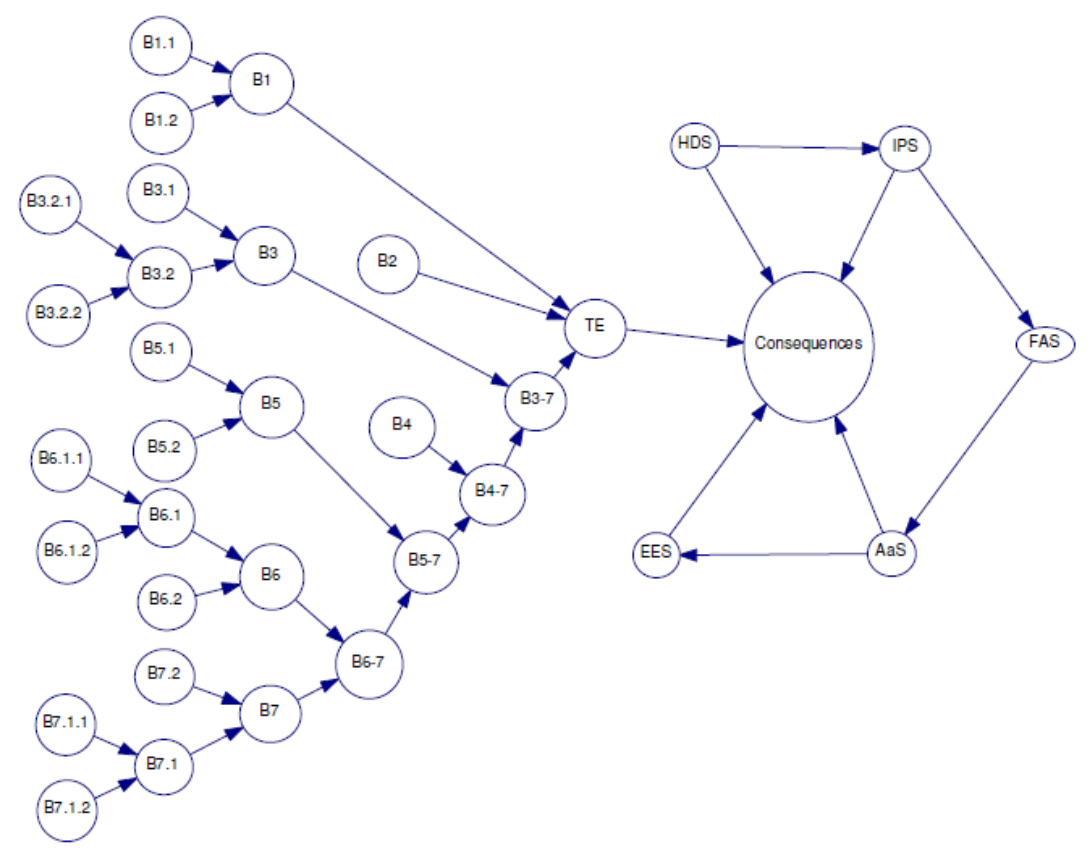

Figure 6. BN model for offshore well P\&A operational failure.

As seen in Fig. 4, the occurrence probability of safety barriers relies on the presence of the other safety barrier to demand its activation. For example, the emergency evacuation system is initiated sequentially following the failure of AaS, accordingly.

\subsection{Step 3: Data Collection and Processing}

The failure probability or reliability of each root node of the BN will be obtained from multiple sources, for example, within the similar sectors such as offshore drilling or completion activities, or completely different industry such as process systems, nuclear or mining decommissioning operations. Where failure events are unfamiliar, or impossible to obtain due to the uniqueness, expert opinion will be sought, in the form of guestimates and possibilities. The data presented in Table 2 is used to demonstrate the applicability of this model.

Table 2. Causal events failure precursor data.

\begin{tabular}{ccccccccccccccccc}
\hline Source & $\begin{array}{c}\text { Duration } \\
\text { of the } \\
\text { leak }\left(N_{i}\right)\end{array}$ & $\mathrm{B}_{2}$ & $\mathrm{~B}_{1.1}$ & $\mathrm{~B}_{1.2}$ & $\mathrm{~B}_{3.1}$ & $\mathrm{~B}_{3.2 .1}$ & $\mathrm{~B}_{3.2 .2}$ & $\mathrm{~B}_{4}$ & $\mathrm{~B}_{5.1}$ & $\mathrm{~B}_{5.2}$ & $\mathrm{~B}_{6.1 .1}$ & $\mathrm{~B}_{6.1 .2}$ & $\mathrm{~B}_{6.2}$ & $\mathrm{~B}_{7.1 .1}$ & $\mathrm{~B}_{7.1 .2}$ & $\mathrm{~B}_{7.2}$ \\
\hline 1 & 1 & - & 2 & 2 & 1 & 1 & - & 1 & - & 3 & 3 & 1 & 3 & - & 8 & 3 \\
2 & 3 & 1 & - & - & - & - & 1 & 1 & - & 1 & 3 & 2 & 1 & - & 1 & 1 \\
3 & 3 & - & - & 1 & 3 & - & 1 & 2 & 2 & - & 1 & 2 & - & - & - & -
\end{tabular}




\begin{tabular}{ccccccccccccccccc}
4 & 1 & 1 & 1 & - & 1 & 1 & - & 3 & - & 5 & - & 1 & 5 & 1 & 1 & 5 \\
5 & 1 & 2 & - & - & - & - & 2 & 3 & 5 & - & 1 & - & - & 2 & 10 & - \\
6 & 2 & 3 & 3 & 4 & - & 3 & 5 & - & 5 & - & 1 & - & - & 3 & 3 & - \\
7 & 5 & 3 & 1 & 1 & 1 & - & 3 & 4 & 4 & 2 & - & - & 2 & 3 & 3 & 2 \\
8 & 1 & 4 & - & - & - & - & 2 & - & - & - & - & 3 & - & 4 & - & - \\
9 & 1 & 5 & 1 & 1 & - & 2 & - & 5 & 6 & 1 & - & - & 1 & 5 & - & 1 \\
10 & 2 & 1 & 1 & 1 & 7 & - & 1 & 7 & 6 & 1 & 1 & - & 1 & 1 & 1 & 1 \\
\hline
\end{tabular}

\subsection{Step 4: HBA modelling}

The failure data obtained from multiple sources from step 4 will be implemented within HBA modelling capabilities to aggregate the set of data into the marginal failure probability assigned to the root nodes as discussed in section 2.2. To fully implement HBA, the number of sources, $n$, the failure data set $x_{i}$, and the specified number of trials or demands, $N_{i}$ are all required to aggregate a suitable single value that would yield the same effect for the root node. HBA can then present these set of data as a distribution from which the suitable single value can be obtained. As noted in section 2.2.2, a failure data dependent on time will be distributed over Poisson likelihood function and those data collected based on mean time to failure (MTTF) will be modelled using exponential likelihood. 

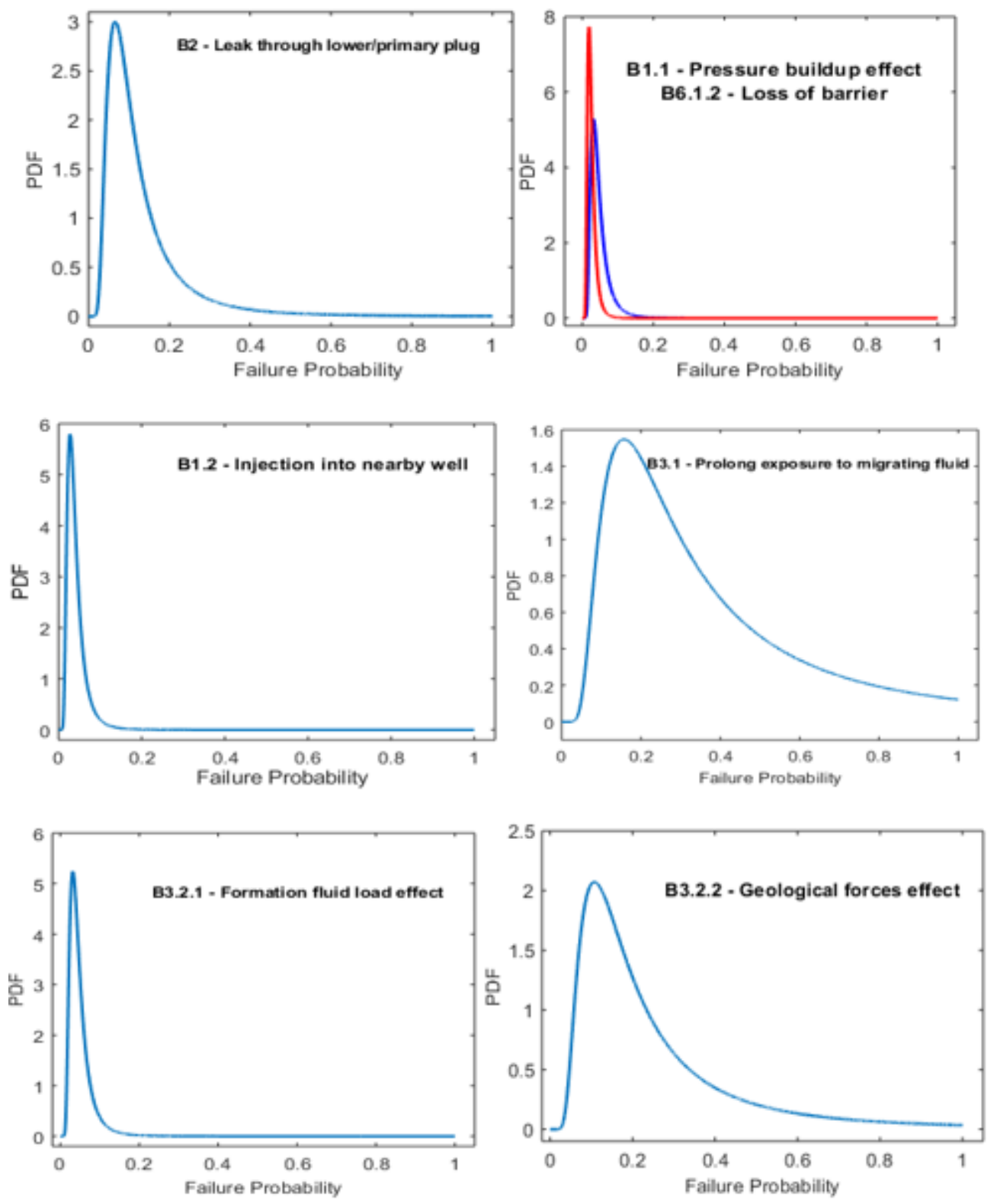

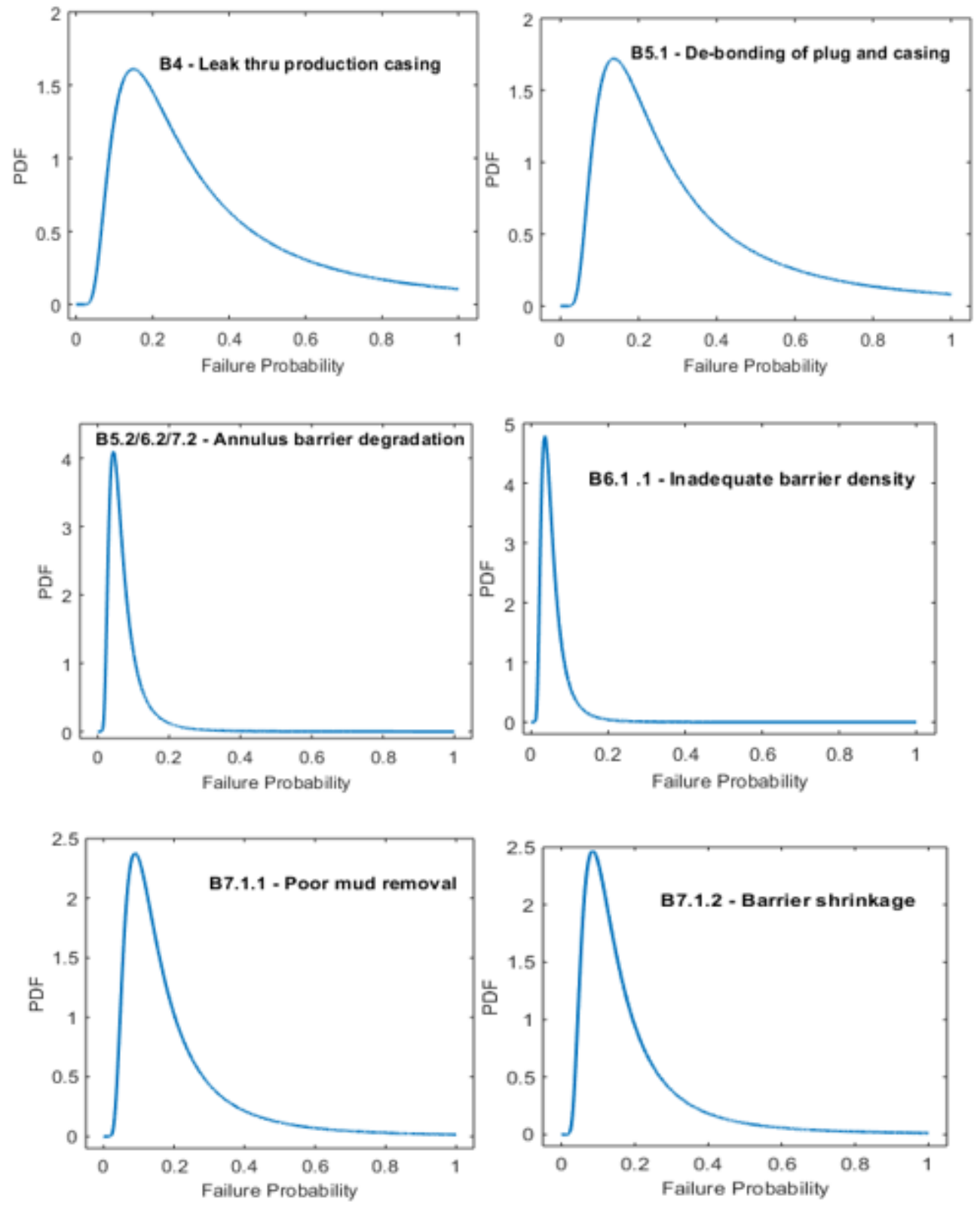

Figure 7. causation events' predictive posterior probability distribution.

The same approach is repeated to compute the occurrence probability of all the implemented safety barriers. 

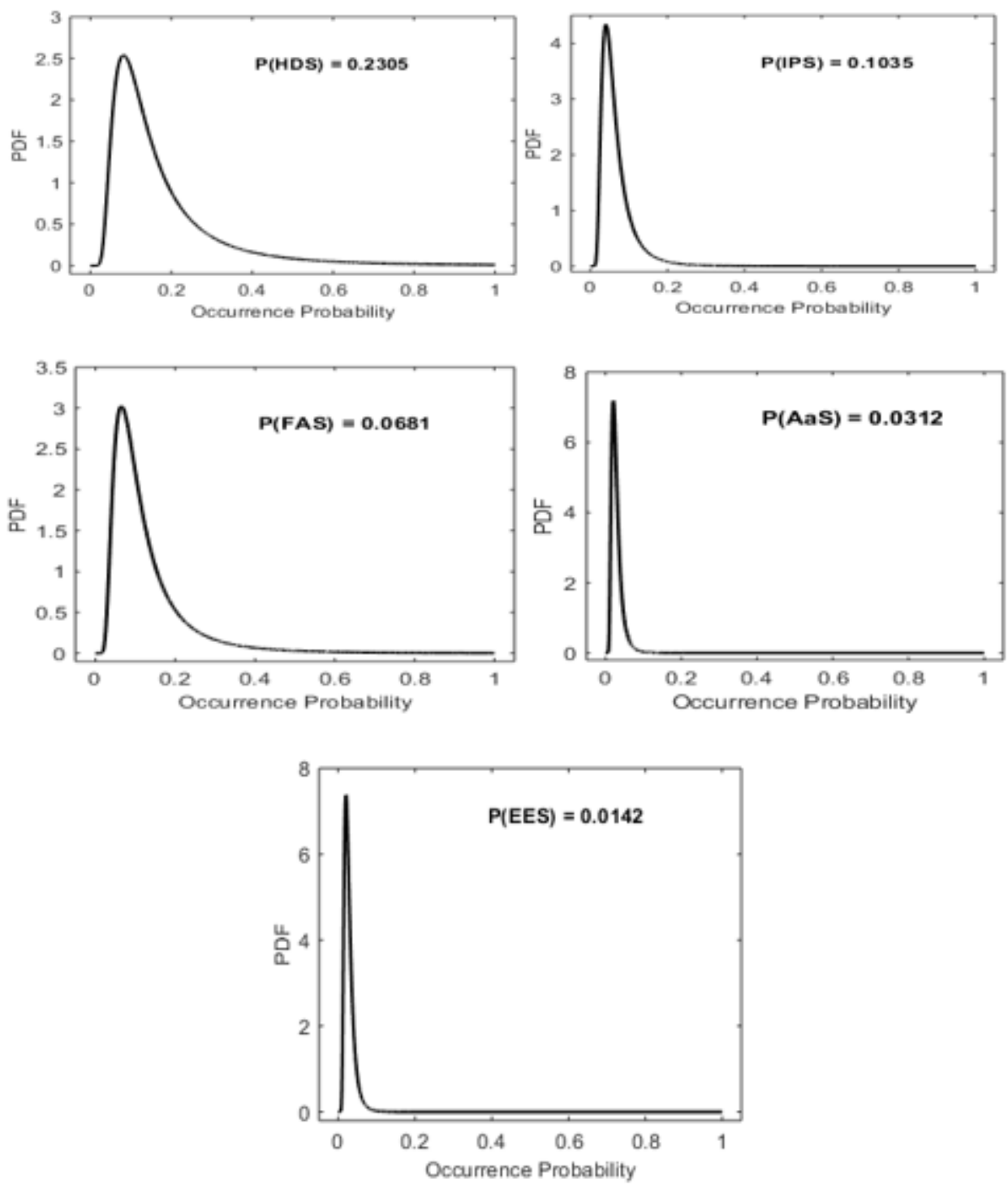

Figure 8. Safety barrier predictive posterior probability distribution.

\subsection{Step 5: Bayesian Network Modelling}

Following the probabilities estimate approach in step 5 and the mapping procedure in step 3, BN will be used to assess and reassess the accident evolution and the interdependencies among interacting events. The interactions among events will be modelled through dependency knowledge and reflected in the CPTs of all child nodes. This information is then used as prior knowledge to predict the probability of an accident. Furthermore, the capability of BN will be 
tested through forward and backward analysis. In the forward analysis, the probability of leaf node will be updated by instantiating one or more of the root nodes to a given state when new knowledge about their occurrence or non-occurrence become available. i.e. $P$ (accident $=$ $\{$ true $\} \mid$ root node $=\{$ fails $\})$. On the other hand, the backward analysis is used to obtain the posterior probability of root nodes given accident occurrence through instantiating the accident event to a specific state, i.e. $P($ root node $=\{$ fail $\} \mid$ accident $=\{$ true $\})$.

\subsection{Step 6: Uncertainty Modelling}

The uncertainty in the model is addressed through the implementation of a leaky parameter of interest as a bounded interval. To elicit the CPT for the leak through the mudline, the values of $l_{o}$ is assumed to vary between 0.00 and 0.005 , respectively, i.e. $0.00 \leq l_{o} \leq 0.005$. The leaky probability boundaries offer the advantage of producing two sets of failure probabilities, which is in practice, realistic in a non-absolute and uncertain analysis. It is to be noted that each of the three causation nodes will be assigned three states, leading to 27 outcomes for each state of the leak through mudline event (pivot node), only 12 of these are shown in Table 5. For the sake of simplicity, 1.0 is assigned to the ignorance $(\mathrm{T}, \mathrm{F})$ model.

Table 3. Top event conditional probability table extract.

\begin{tabular}{|c|c|c|c|c|c|c|}
\hline \multirow[b]{2}{*}{$\mathrm{B}_{1}$} & \multirow[b]{2}{*}{$\mathrm{B}_{2}$} & \multirow[b]{2}{*}{$\mathrm{B}_{3-7}$} & \multicolumn{3}{|c|}{ Link probability } & \multirow[t]{2}{*}{ TE failure CPT } \\
\hline & & & $\mathrm{P}_{\mathrm{F}}$ & $\mathrm{P}_{\mathrm{T}}$ & $\mathrm{P}_{\mathrm{T}, \mathrm{F}}$ & \\
\hline $\mathrm{T}$ & $\mathrm{T}$ & $\mathrm{T}$ & 0.005 & 0.090 & 0.905 & $0.005 \cdot(0.181) \bullet(0.190) \bullet(0.00038)$ \\
\hline $\mathrm{T}$ & $\mathrm{T}$ & $\mathrm{F}$ & 0.688 & 0.310 & 0.002 & $0.688 \bullet(0.181) \bullet(0.190) \bullet(1-0.00038)$ \\
\hline $\mathrm{T}$ & $\mathrm{F}$ & $\mathrm{T}, \mathrm{F}$ & 0.765 & 0.015 & 0.220 & $0.765 \bullet(0.181) \bullet(1-0.190) \bullet 1.0$ \\
\hline $\mathrm{T}$ & $\mathrm{F}$ & $\mathrm{T}$ & 0.873 & 0.007 & 0.120 & $0.873 \bullet(0.181) \bullet(1-0.190) \bullet(0.00038)$ \\
\hline $\mathrm{F}$ & $\mathrm{T}, \mathrm{F}$ & $\mathrm{F}$ & 0.663 & 0.130 & 0.207 & $0.663 \cdot(1-0.181) \bullet 1.0 \bullet(1-0.00038)$ \\
\hline $\mathrm{F}$ & $\mathrm{T}, \mathrm{F}$ & $\mathrm{T}, \mathrm{F}$ & 0.222 & 0.108 & 0.670 & $0.222 \bullet(1-0.181) \bullet 1.0 \bullet 1.0$ \\
\hline $\mathrm{F}$ & $\mathrm{T}$ & $\mathrm{T}$ & 0.815 & 0.085 & 0.100 & $0.815 \bullet(1-0.181) \bullet(0.190) \bullet(0.00038)$ \\
\hline $\mathrm{F}$ & $\mathrm{T}$ & $\mathrm{F}$ & 0.238 & 0.680 & 0.082 & $0.237 \bullet(1-0.181) \bullet(0.190) \bullet(1-0.00038)$ \\
\hline $\mathrm{T}, \mathrm{F}$ & $\mathrm{F}$ & $\mathrm{T}, \mathrm{F}$ & 0.081 & 0.901 & 0.018 & $0.081 \bullet 1.0 \bullet(1-0.190) \bullet 1.0$ \\
\hline $\mathrm{T}, \mathrm{F}$ & $\mathrm{F}$ & $\mathrm{T}$ & 0.975 & 0.009 & 0.016 & $0.975 \cdot 1.0 \bullet(1-0.190) \bullet(0.00038)$ \\
\hline $\mathrm{T}, \mathrm{F}$ & $\mathrm{T}, \mathrm{F}$ & $\mathrm{F}$ & 0.075 & 0.204 & 0.721 & $0.075 \bullet 1.0 \bullet 1.0 \bullet(1-0.00038)$ \\
\hline \multirow[t]{2}{*}{$\mathrm{T}, \mathrm{F}$} & $\mathrm{T}, \mathrm{F}$ & $\mathrm{T}, \mathrm{F}$ & 0.001 & 0.409 & 0.590 & $0.001 \cdot 1.0 \cdot 1.0 \cdot 1.0$ \\
\hline & & & & & & $\Sigma \mathrm{P}($ leak thru mudline $)=0.513$ \\
\hline
\end{tabular}




\subsection{Step 7: Updating Failure Evidence}

New evidence obtained through the predictive posterior distributions within HBA or entirely new data collected through real-time monitoring of the plugging and abandonment operation can be feed into the BN to update the degree of belief. In this study, failure probability updating is conducted through the instantiation of selected nodes to a specific state to obtain up-to-date posterior probabilities in both forward and backward analysis (Khakzad et al., 2013a; Bobbio et al., 2001).

\section{$4 \quad$ Result and discussion}

With the understanding that the accident was caused by the failure of mechanical barriers such as the isolation zone plug and the primary plug, the well P\&A operational failure probabilities are as depicted in Fig. 7 and 8. The well P\&A operational failure became imminent following the failure of these barriers. Table 4 showed the failure probabilities obtained through aggregation within HBA to address the concerns about data sparsity and source-to-source variability. It is to be noted that the failure data used in this study are those where dependencies among causations are considered (Table 4, column 5), and the dependencies are implemented within the CPTs using the imprecise leaky noisy-OR. Independent modelling of the events yields the same results in both conventional BT and BN (Table 4, column 4) which further confirms the efficiency of BN in dependency analysis.

Table 4. Occurrence prior probabilities of causal events.

\begin{tabular}{ccccc}
\hline \multirow{2}{*}{ Symbol } & \multirow{2}{*}{ EVENT DESCRIPTION } & \multirow{2}{*}{ Data Sources } & \multicolumn{2}{c}{ Failure probabilities } \\
\cline { 4 - 5 } & & independence & dependency \\
\hline $\mathrm{B}_{1.1}$ & Pressure buildup & Aggregate & $8.50 \mathrm{E}-02$ & $8.50 \mathrm{E}-02$ \\
$\mathrm{~B}_{1.2}$ & Injection into nearby well & Aggregate & $1.05 \mathrm{E}-01$ & $1.05 \mathrm{E}-01$ \\
$\mathrm{~B}_{1}$ & Leak through zone isolation & AND-gate & $1.81 \mathrm{E}-01$ & $2.13 \mathrm{E}-01$ \\
$\mathrm{~B}_{2}$ & Leak through lower/primary & Aggregate & $1.90 \mathrm{E}-01$ & $1.90 \mathrm{E}-01$
\end{tabular}




\begin{tabular}{|c|c|c|c|c|}
\hline $\mathrm{B}_{3}$ & $\begin{array}{l}\text { Leak through upper/secondary } \\
\text { plug }\end{array}$ & OR-gate & $1.37 \mathrm{E}-03$ & $1.84 \mathrm{E}-03$ \\
\hline $\mathrm{B}_{3.1}$ & $\begin{array}{l}\text { Prolong exposure to migrating } \\
\text { fluid }\end{array}$ & Aggregate & $1.47 \mathrm{E}-01$ & $1.47 \mathrm{E}-01$ \\
\hline $\mathrm{B}_{3.2}$ & Yielding of casing & OR-gate & $9.29 \mathrm{E}-03$ & $1.02 \mathrm{E}-02$ \\
\hline $\mathrm{B}_{3-7}$ & $\begin{array}{c}\text { Combined leak through upper } \\
\text { plug }\end{array}$ & OR-gate & $3.80 \mathrm{E}-04$ & $3.90 \mathrm{E}-04$ \\
\hline $\mathrm{B}_{3.2 .1}$ & Formation fluids load effect & Aggregate & $5.00 \mathrm{E}-02$ & 5.00E-02 \\
\hline $\mathrm{B}_{3.2 .2}$ & Geological forces effect & Aggregate & $1.86 \mathrm{E}-01$ & $1.86 \mathrm{E}-01$ \\
\hline $\mathrm{B}_{4}$ & Leak through production plug & Aggregate & $2.75 \mathrm{E}-01$ & $2.75 \mathrm{E}-01$ \\
\hline $\mathrm{B}_{4-7}$ & $\begin{array}{l}\text { Combined leak thru annulus- } \\
\text { production casing }\end{array}$ & AND-gate & 2.79E-01 & 2.89E-01 \\
\hline $\mathrm{B}_{5}$ & Leak through casing assembly & OR-gate & $3.54 \mathrm{E}-02$ & $3.89 \mathrm{E}-02$ \\
\hline $\mathrm{B}_{5.1}$ & De-bonding of plug and casing & Aggregate & $2.95 \mathrm{E}-01$ & 2.95E-01 \\
\hline $\mathrm{B}_{5.2}$ & Annulus barrier degradation & Aggregate & $1.20 \mathrm{E}-01$ & $1.20 \mathrm{E}-01$ \\
\hline $\mathrm{B}_{5-7}$ & Leak through annulus barrier & OR-gate & $5.49 \mathrm{E}-03$ & $6.01 \mathrm{E}-03$ \\
\hline $\mathrm{B}_{6}$ & Leak through conductor casing & OR-gate & $6.10 \mathrm{E}-04$ & $2.06 \mathrm{E}-03$ \\
\hline $\mathrm{B}_{6.1}$ & Insufficient barrier length & OR-gate & $5.05 \mathrm{E}-03$ & $5.62 \mathrm{E}-03$ \\
\hline $\mathrm{B}_{6.1 .1}$ & Inadequate barrier density & Aggregate & $5.95 \mathrm{E}-02$ & 5.95E-02 \\
\hline $\mathrm{B}_{6.1 .2}$ & Loss of barrier & Aggregate & $8.50 \mathrm{E}-02$ & $8.50 \mathrm{E}-02$ \\
\hline $\mathrm{B}_{6.2}$ & Annulus barrier degradation & Aggregate & $1.20 \mathrm{E}-01$ & $1.20 \mathrm{E}-01$ \\
\hline $\mathrm{B}_{6-7}$ & $\begin{array}{l}\text { Leak through surface-annulus } \\
\text { barriers }\end{array}$ & AND-gate & $1.55 \mathrm{E}-01$ & $1.27 \mathrm{E}-01$ \\
\hline $\mathrm{B}_{7}$ & Leak through casing hanger & AND-gate & $1.55 \mathrm{E}-01$ & $1.69 \mathrm{E}-01$ \\
\hline $\mathrm{B}_{7.1}$ & Contamination of barrier & OR-gate & $3.90 \mathrm{E}-02$ & $4.21 \mathrm{E}-02$ \\
\hline $\mathrm{B}_{7.1 .1}$ & Poor mud removal & Aggregate & $1.75 \mathrm{E}-01$ & $1.75 \mathrm{E}-01$ \\
\hline $\mathrm{B}_{7.1 .2}$ & Barrier shrinkage & Aggregate & $2.25 \mathrm{E}-01$ & 2.25E-01 \\
\hline $\mathrm{B}_{7.2}$ & Annulus barrier degradation & Aggregate & $1.20 \mathrm{E}-01$ & $1.20 \mathrm{E}-01$ \\
\hline
\end{tabular}

For the safety barriers (Table 5), their failure rates are estimated for a seven-week for which the Elgin abandonment operation failed without consideration for the accident evolution over this period. The well P \& A schematic investigated in this study is assumed to conform to the minimum plugging requirements set out in NORSOK D-010, that is, with at least two cement barriers and a mechanical plug. Although, the number of barriers required depends on some factors such as geological location, the operator's policy and regional best practices. Also, the state variables of the root and safety nodes are assumed to be binary that is, 'works or fails' to illustrate the 
occurrence and non-occurrence of the events. On the other hand, the intermediate nodes leading to the occurrence of the leak through mudline (top event) all have three states (true/false/true, false) to account for the uncertainty of modelled data, elicitation of CPTs, and un-modelled parameters. The states of the leaf node, $C_{i}$ are binary with six outcomes.

Table 5. Occurrence probabilities of safety barriers.

\begin{tabular}{ccc}
\hline Symbol & Barrier description & $\begin{array}{l}\text { Failure } \\
\text { probabilities }\end{array}$ \\
\hline HDS & Hydrocarbon detection sensor & $2.31 \mathrm{E}-01$ \\
IPS & Ignition prevention system & $1.04 \mathrm{E}-01$ \\
FAS & Flame arrestor system & $6.81 \mathrm{E}-02$ \\
AaS & Alarm and sprinkler & $3.12 \mathrm{E}-02$ \\
EES & Emergency evacuation system & $1.42 \mathrm{E}-02$ \\
\hline
\end{tabular}

\section{1 $\underline{\text { Consequence analysis }}$}

The consequence events are investigated by modelling the CPTs of the leak through mudline as discussed in section 3.7 for the initial leak probability. Initiating the BN solver in Fig. 6 with marginal probabilities for all root nodes obtained the HBA and CPTs for all child nodes, it is observed that a leak through mudline prior failure probability of 0.51346 yields the occurrence prior probabilities of all the consequence outcomes as shown in Table 6, column 4. This top event prior probability is due to failures emanating from leaks through the zone isolation plug (0.18108), the primary/lower plug (0.19000) and the upper/secondary plug $(0.000381)$. 


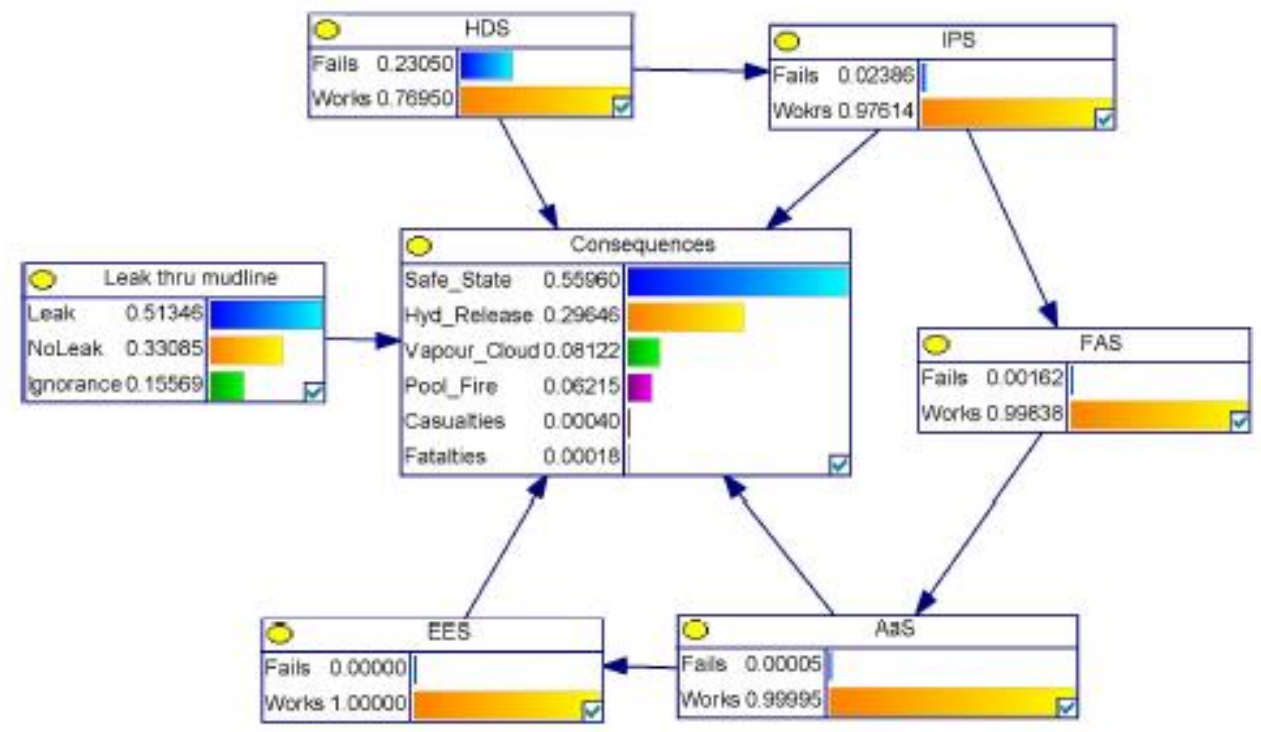

Figure 9. Microanalysis of consequence dependency on the top event.

Table 6. Occurrence probabilities of consequence events.

\begin{tabular}{cccccc}
\hline \multirow{2}{*}{ Symbol } & Attributes & \multirow{2}{*}{ CONSEQUENCE DESCRIPTION } & \multicolumn{3}{c}{ Failure probabilities } \\
\cline { 4 - 6 } & $\mathrm{C}_{1}$ & Safe State & $l_{o}$ & $l_{o}^{-}$ & $l_{o}^{+}$ \\
$\mathrm{C}_{2}$ & $\begin{array}{c}\text { Hydrocarbon } \\
\text { Release }\end{array}$ & $\begin{array}{c}\text { Safe condition } \\
\text { Near miss with no remediation } \\
\text { required }\end{array}$ & $5.60 \mathrm{E}-1$ & $4.92 \mathrm{E}-1$ & $9.76 \mathrm{E}-01$ \\
$\mathrm{C}_{3}$ & Vapor Cloud & $\begin{array}{c}\text { The incident with minor injuries } \\
\text { and equipment loss }\end{array}$ & $8.96 \mathrm{E}-1$ & $2.26 \mathrm{E}-1$ & $3.41 \mathrm{E}-01$ \\
$\mathrm{C}_{4}$ & Pool Fire & $\begin{array}{c}\text { Accident with fire, few deaths } \\
\text { and a minor spill }\end{array}$ & $1.61 \mathrm{E}-2$ & $9.42 \mathrm{E}-02$ \\
$\mathrm{C}_{5}$ & Casualties & $\begin{array}{c}\text { Accident with fatalities, } \\
\text { explosions and major spill }\end{array}$ & $5.52 \mathrm{E}-2$ & $7.79 \mathrm{E}-02$ \\
$\mathrm{C}_{6}$ & Fatalities & $\begin{array}{c}\text { A catastrophe with fatalities, rig } \\
\text { loss and a considerable spill }\end{array}$ & $1.80 \mathrm{E}-4$ & $1.17 \mathrm{E}-5$ & $2.08 \mathrm{E}-4$ \\
\hline
\end{tabular}

\subsection{Model validation}

The model is validated through leaky probability's lower and upper bounds to investigate the applicability of the framework in practice. The minimum and maximum leak probabilities in the analysis are sequentially incorporated. That is, 5.00E-3 is replaced with $2.00 \mathrm{E}-3$ and $1.00 \mathrm{E}-2$, separately. These values demonstrate the influence of un-modelled parameters such as uncaptured reservoir conditions during the hazard identification process and unknown failure data and uncertainty in the leak and link probability assignments. Re-running the analysis yield a notable change in the occurrence probability of the leak through mudline from $5.13 \mathrm{E}-1$ to $2.25 \mathrm{E}-1$ and 
9.33E-1, respectively. With the lower bound value, the occurrence probability of the accident is seen to decrease by $56 \%$. Whereas an increase of $82 \%$ is obtained for the upper bound value, indicating that a high leaky probability would imply a conservative risk analysis. Accordingly, the occurrences of the consequence events are seen to have increased considerably with an increased leaky probability (Table 6). This result can provide invaluable insight into the acceptable risk tolerance to be put in place during the P \& A operation. The imprecise LN-OR further confirms the importance of a thorough understanding of the hazards in a permanent well abandonment operation.

\subsection{Probability Updating}

To estimate the posterior probabilities of the model when new evidence of any or all the accident causations become available, selected root nodes are instantiated to 'failed' state. For instance, instantiating $B_{1}, B_{2}$, and $B_{5}$ through forwarding analysis leads to a $71 \%$ increase in the safe state; $78 \%$ in the hydrocarbon release; $77 \%$ in vapor cloud; $62 \%$ in the pool fire; $82 \%$ in the casualties; and $8 \%$ in the fatality's occurrence probabilities. The results show that the occurrence of casualties' event $C_{5}$ is the most probable consequence. Similarly, by instantiating the consequence node $C_{1}$ as new evidence through backward analysis, the posterior probabilities of all nodes are obtained and presented as shown in Table 7. The leak through mudline failure increased by $47 \%$ leading to 35\% increase in the leak through zone isolation plug; 34\% leak through lower (primary) plug; and, $47 \%$ increase in the combined leak through the upper plug.

\section{4 $\underline{\text { Safety-critical analysis }}$}

The non-occurrence of the devastating accidents is dependent on the strength of influence of each contributory causation. Some of the causations are more influential than others, and it is essential to identify these through sensitivity analysis. Sensitivity analysis is performed by instantiating either the leak through mudline failure or the most devastating consequence to $100 \%$, through 
backward propagation. Concerning the ILN-OR formalism with leak probability of $0.5 \%$, the consequence 'vapor cloud' is instantiated and the updated (posterior) probabilities of the causations (root nodes) are obtained and recorded as shown in Table 7. Comparing the prior and posterior probabilities alone is not enough to make certain safety improvements to the whole abandonment operation, as all causations tend to increase by varying factors. Therefore, a ratio of variation, $\mathrm{IM}^{\mathrm{ROV}}$ gave in Eq. 10 is adopted.

$$
I M^{R O V}\left(\mathrm{~B}_{i}\right)=\left|\frac{\beta\left(\mathrm{B}_{i}\right)}{\alpha\left(\mathrm{B}_{i}\right)}-1\right|
$$

Where $\alpha\left(\mathrm{B}_{i}\right)$ and $\beta\left(\mathrm{B}_{i}\right)$ are the prior and posterior probabilities of events $\mathrm{B}_{i}$.
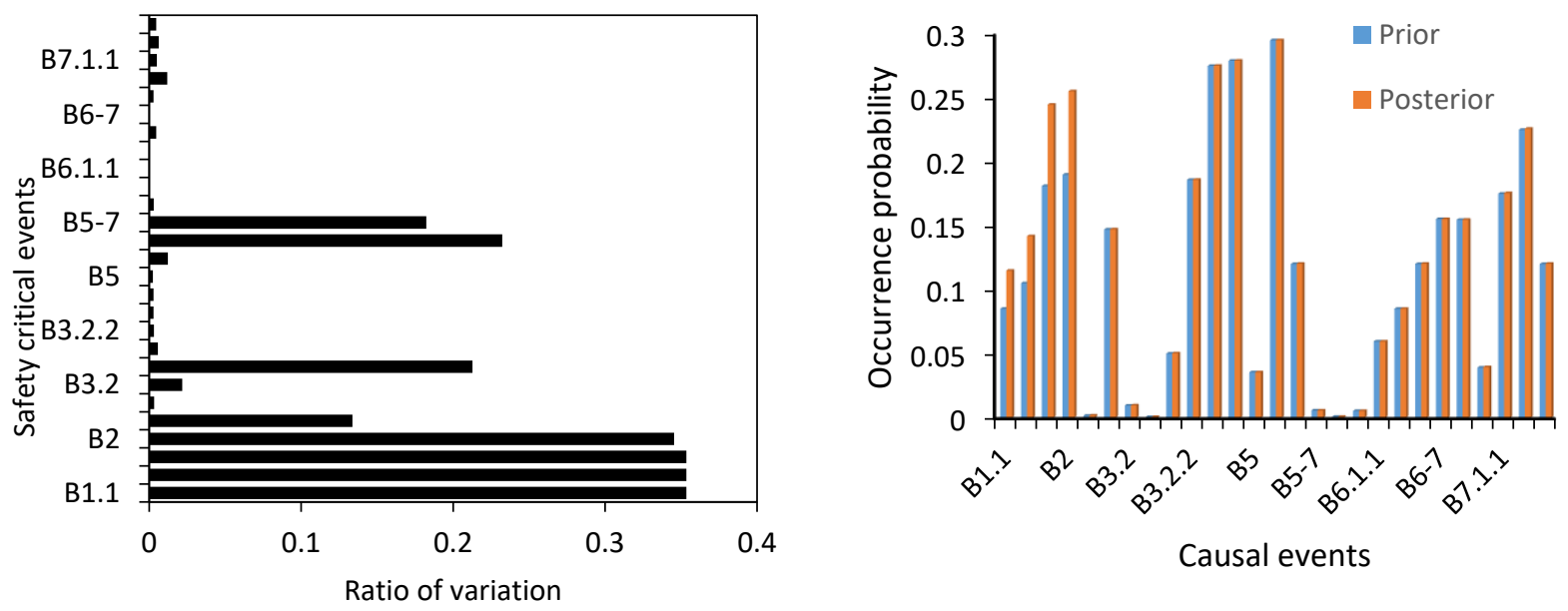

Figure 10. Critical events response to fire and explosion occurrence.

A closer look at Table 7 , column 5 revealed that the leak through zonal isolation plug $\left(B_{1}\right)$, injection into nearby well $\left(\mathrm{B}_{1.2}\right)$, leak through the lower/primary plug $\left(\mathrm{B}_{2}\right)$, and the formation fluids pressure build-up $\left(\mathrm{B}_{1.1}\right)$ are the critical safety events that require the highest amount of resource allocation. Also, the leak through the upper/secondary plug $\left(\mathrm{B}_{2}\right)$, combined leak through the upper/secondary plug $\left(\mathrm{B}_{3-7}\right)$ and the degradation of annulus barrier are also responsive to the slightest change in the consequences' variation, indicating that safety measures are necessary to prevent escalating the accidents. For instance, the occurrence of the vapor cloud would have been 
caused by a failure of the topmost barrier plug leading to hydrocarbon leakage through the mudline by $79.3 \%$.

Table 7. Comparison of prior and posterior probabilities of critical nodes.

\begin{tabular}{|c|c|c|c|c|}
\hline \multirow[b]{2}{*}{ Symbol } & \multirow[b]{2}{*}{ FAILURE DESCRIPTION } & \multicolumn{3}{|c|}{ Failure probabilities with $l_{o}$} \\
\hline & & prior & posterior & $\mathrm{IM}^{\mathrm{ROV}}(\%)$ \\
\hline $\mathrm{B}_{1.1}$ & Pressure buildup & $8.50 \mathrm{E}-2$ & $1.15 \mathrm{E}-1$ & 35.12 \\
\hline $\mathrm{B}_{1.2}$ & Injection into nearby well & $1.05 \mathrm{E}-1$ & $1.42 \mathrm{E}-1$ & 35.12 \\
\hline $\mathrm{B}_{1}$ & $\begin{array}{l}\text { Leak through zone isolation } \\
\text { plug }\end{array}$ & $1.81 \mathrm{E}-1$ & $2.45 \mathrm{E}-1$ & 35.12 \\
\hline $\mathrm{B}_{2}$ & $\begin{array}{l}\text { Leak through lower/primary } \\
\text { plug }\end{array}$ & $1.90 \mathrm{E}-1$ & $2.55 \mathrm{E}-1$ & 34.31 \\
\hline $\mathrm{B}_{3}$ & $\begin{array}{l}\text { Leak through upper/secondary } \\
\text { plug }\end{array}$ & $1.37 \mathrm{E}-3$ & $1.55 \mathrm{E}-3$ & 13.14 \\
\hline $\mathrm{B}_{3.1}$ & $\begin{array}{l}\text { Prolong exposure to migrating } \\
\text { fluid }\end{array}$ & $1.47 \mathrm{E}-1$ & $1.47 \mathrm{E}-1$ & 0.10 \\
\hline $\mathrm{B}_{3.2}$ & Yielding of casing & $9.29 \mathrm{E}-3$ & $9.47 \mathrm{E}-3$ & 1.94 \\
\hline $\mathrm{B}_{3-7}$ & $\begin{array}{l}\text { Combined leak through upper } \\
\text { plug }\end{array}$ & $3.80 \mathrm{E}-4$ & 4.60E-4 & 21.05 \\
\hline $\mathrm{B}_{3.2 .1}$ & Formation fluids load effect & $5.00 \mathrm{E}-2$ & $5.02 \mathrm{E}-2$ & 0.34 \\
\hline $\mathrm{B}_{3.2 .2}$ & Geological forces effect & $1.86 \mathrm{E}-1$ & $1.86 \mathrm{E}-1$ & 0.08 \\
\hline $\mathrm{B}_{4}$ & Leak through production plug & $2.75 \mathrm{E}-1$ & $2.75 \mathrm{E}-1$ & 0.05 \\
\hline $\mathrm{B}_{4-7}$ & $\begin{array}{l}\text { Combined leak thru annulus- } \\
\text { production casing }\end{array}$ & $2.78 \mathrm{E}-1$ & $2.79 \mathrm{E}-1$ & 0.05 \\
\hline $\mathrm{B}_{5}$ & Leak through casing assembly & $3.54 \mathrm{E}-2$ & $3.54 \mathrm{E}-2$ & 0.01 \\
\hline $\mathrm{B}_{5.1}$ & De-bonding of plug and casing & $2.95 \mathrm{E}-1$ & $2.95 \mathrm{E}-1$ & 0.01 \\
\hline $\mathrm{B}_{5.2}$ & Annulus barrier degradation & $1.20 \mathrm{E}-1$ & $1.20 \mathrm{E}-1$ & 0.23 \\
\hline $\mathrm{B}_{5-7}$ & Leak through annulus barrier & $5.49 \mathrm{E}-3$ & $5.50 \mathrm{E}-3$ & 0.18 \\
\hline $\mathrm{B}_{6}$ & Leak through conductor casing & $6.10 \mathrm{E}-4$ & $6.10 \mathrm{E}-4$ & 0.07 \\
\hline$B_{6.1}$ & Insufficient barrier length & $5.05 \mathrm{E}-3$ & $5.05 \mathrm{E}-3$ & 0.00 \\
\hline $\mathrm{B}_{6.1 .1}$ & Inadequate barrier density & $5.95 \mathrm{E}-2$ & $5.95 \mathrm{E}-2$ & 0.00 \\
\hline $\mathrm{B}_{6.1 .2}$ & Loss of barrier & $8.50 \mathrm{E}-2$ & $8.50 \mathrm{E}-2$ & 0.00 \\
\hline $\mathrm{B}_{6.2}$ & Annulus barrier degradation & $1.20 \mathrm{E}-1$ & $1.20 \mathrm{E}-1$ & 0.23 \\
\hline $\mathrm{B}_{6-7}$ & $\begin{array}{l}\text { Leak through surface-annulus } \\
\text { barriers }\end{array}$ & $1.55 \mathrm{E}-1$ & $1.55 \mathrm{E}-1$ & 0.00 \\
\hline $\mathrm{B}_{7}$ & Leak through casing hanger & $1.55 \mathrm{E}-1$ & $1.55 \mathrm{E}-1$ & 0.05 \\
\hline $\mathrm{B}_{7.1}$ & Contamination of barrier & $3.90 \mathrm{E}-2$ & $3.94 \mathrm{E}-2$ & 0.96 \\
\hline $\mathrm{B}_{7.1 .1}$ & Poor mud removal & $1.75 \mathrm{E}-1$ & $1.75 \mathrm{E}-1$ & 0.27 \\
\hline $\mathrm{B}_{7.1 .2}$ & Barrier shrinkage & $2.25 \mathrm{E}-1$ & $2.26 \mathrm{E}-1$ & 0.40 \\
\hline $\mathrm{B}_{7.2}$ & Annulus barrier degradation & $1.20 \mathrm{E}-1$ & $1.20 \mathrm{E}-1$ & 0.23 \\
\hline
\end{tabular}

The approach in this study is limited in its applications due to the potential errors associated with the analogous data which may not represent specific hazard during well P\&A, and the estimation of the leak probability that cannot be empirically calculated from sparse data. In addition, the focus 
of this model is on offshore wells and minor modifications may be required to address other types of wells. However, as the decommissioning operations become matured and reliable data collected, a case-specific failure analysis can be performed with significant reduction of uncertainty.

\section{Conclusions}

The present study investigates the uncertainty related to unknown reservoir conditions which may complicate the safety of offshore wells undergoing plugging and abandonment operation. The P\&A operational failure analysis is conducted using a Hierarchical Bayesian model. The model assists in estimating the aggregate failure probabilities of causations. This model is tested in the abandonment of oil and gas wells where knowledge of hazards in its entirety is vague, and data is sparse.

Furthermore, the obtained probabilities are used in the Bayesian network to model comprehensive accident evolution and the uncertainty using appropriate relaxation technique. The Bayesian network also accounted for the dependencies amongst interacting causations. The relaxation technique introduced here, is based on an imprecise leaky noisy-OR gate formalism, to account for the uncertainty in modelling parameters, parameter relaxation, and uncaptured hazards during the hazard identification process. The relaxation technique enabled the probability values to be presented at interval, with lower and upper bounds. The upper bound represents a conservative safety analysis and offers decision-makers the advantage to develop a safety improvement strategy within these bounds, making this approach practical. This is confirmed by the $82 \%$ increase as the base case analysis with $l_{o}=5.00 E-3$ is replaced with upper bound where $l_{o}^{+}=1.00 E-2$, whereas a reduction of $56 \%$ is recorded when $l_{o}^{-}$is substituted for $l_{o}$. Through model validation, an occurrence of the safe state consequence yielded a corresponding up-to-date probability of leak causations. Safety-critical analysis conducted through the ratio of variation further indicated that the leak through the lower plug, leak through zonal isolation plug, injection into nearby well, and 
the formation fluids pressure build-up within the wellbore are the most sensitive events leading to the eventual leak of hydrocarbon through the mudline and consequent accident evolution. The forward propagation analysis conducted by instantiating selective causation events to 'fail' states, revealed that casualties' event $C_{5}$ is the most critical consequence, evidenced by an $82 \%$ increase from its prior.

The main contribution of this study is in the development and application of the (i) HBA model to obtain aggregated mean of failure data emanating from different sources, and (ii) imprecise leaky parameter which helped to quantify overall uncertainty, thereby providing complete, comprehensive and realistic safety improvement for well plugging and abandonment decisionmakers. The notable results of this study indicate that the safety analysis requires non-absolute probabilities to provide the boundary of values from which acceptable risk tolerance may be estimated.

The practical advantage of the developed HBA model is in its application to offshore oil and gas wells based on sparse data, reservoir evolution and parameters uncertainty. The applicability of the model is limited by post-abandonment failure evolution, onshore wells and estimation of $l_{o}$ due to lack of actual data. Future studies following from this work will examine cascading of failure among the barriers within the wellbore; dynamic hierarchical $\mathrm{BN}$ to provide insight into the sequence of failure over time; and the concept of copula to investigate the failure of well plugging and abandonment from averaging probabilistic perspective.

\section{Acknowledgements}

The authors thankfully acknowledge the funding provided by the John Blackburn Main fellowship granted through the Institute of Marine Engineering, Science and Technology (IMarEST), United Kingdom; and the Natural Science and Engineering Council of Canada and the Canada Research Chair (CRC) Tier I Program in offshore safety and risk engineering. 


\section{References}

Amir Gergerechi, Eigil Sorensen, Jan Erik Jensen. 2016. Report of the investigation of the well control incident in well 31/2-G-4BY1H/BY2H on the Troll field with Songa Endurance drilling unit. <http://www.ptil.no/getfile.php/ > (accessed on July 20, 2018).

Antonucci, A., 2011. The imprecise noisy-OR gate. In: 2011 Proceedings of the $14^{\text {th }}$ International Conference on Information Fusion (FUSION). IEEE, pp. 1-7.

Arzaghi, E., Abaei, M.M., Abbassi, R., Garaniya, V., Binns, J., Chin, C., Khan, F., 2018. A hierarchical Bayesian approach to modelling fate and transport of oil released from subsea pipelines. Journal of Process Safety and Environmental Protection. 118, 307-315.

Babaleye, A. \& Kurt, E.R., 2019. Safety Analysis of Offshore Decommissioning Operation through Bayesian Network. Journal of Ships and Offshore Structures. https://doi.org/10.1080/17445302.2019.1589041.

Babaleye, A., Kurt, E.R., Khan, F., 2019. Safety Analysis of plugging and abandonment of oil and gas wells in uncertain conditions with limited data. Journal of Reliability Engineering and System, 188, 131-141.

Bachu, S. \& Watson, T. L. 2009. Review of failures for wells used for $\mathrm{CO}_{2}$ and acid gas injection in Alberta, Canada. Energy Procedia, 1, 3531-3537.

Badreddine, A., Ben Amor, N., 2010. A dynamic barriers implementation in Bayesian-based bowtie diagrams for risk analysis. In: Proceedings of International Conference on Computer Systems and Applications, pp. 1-8.

Bobbio, A., Portinale, L., Minichino, M., Ciancamerla, E., 2001. Improving the analysis of dependable systems by mapping FTs into Bayesian networks. Journal of Reliability Engineering and System Safety, 71, 249-260.

Chakraborty, S., and Chowdhury, R., 2017, "Hybrid Framework for the Estimation of Rare Failure Event Probability," Journal of Engineering Mechanics (published ahead of print).

El-Gheriani, M., Khan, F., Chen, D and Abbassi, R., 2017a. Major Accident Modelling Using Spare Data. Journal of Process Safety and Environmental Protection. 106: 52-59.

El-Gheriani, M., Khan, F., Chen, D and Abbassi, R., 2017b. Rare Event Analysis Considering Data and Model Uncertainty. ASCE-ASME Journal of Risk and Uncertainty in Engineering Systems, Part B: Mechanical Engineering. 3:1-15.

Fallet-Fidry, G., Weber P., Simon C., Iung B., Duval C., 2012. Evidential network-based extension of Leaky Noisy-OR structure for supporting risks analyses. $8^{\text {th }}$ IFAC Symposium on Fault Detection, Supervision and Safety of Technical Processes (SAFEPROCESS). Mexico City, Mexico. August 29-31.

Ferson, S., 2005. Bayesian methods in risk assessment. Unpublished Report Prepared for the Bureau de Recherches Geologiques et Minieres (BRGM). New York.

Hua, B., Bie, Z., Au, S. K., Li, W., and Wang, X., 2015, "Extracting Rare Failure Events in Composite System Reliability Evaluation Via Subset Simulation," IEEE Trans. Power System. 30(2): 753-762.

Kelly, D., and Smith, C. L., 2011. Bayesian inference for probabilistic risk assessment: A practitioner's guidebook. Springer Science and Business Media.

Kelly, D. L., and Smith, C. L., 2009. Bayesian inference in probabilistic risk assessment: the current state of the art. Journal of Reliability Engineering \& System Safety. 94(2): 628-643.

Khakzad, N., Khan, F., Amyotte, P., 2013a. Dynamic safety analysis of process systems by mapping bow-tie into the Bayesian network. Process Saf. Environ. Prot. 91: 46-53. 
Kiran, R., Teodoriu, C., Dadmohammadi, Y., Nygaard, R., Wood, D., Mokhtari, M., Salehi, S., 2017. Identification and evaluation of great integrity and causes of failure of well integrity barriers (A review). Journal of Natural Gas Science and Engineering. 45: 511-526.

Li, J., Li, J., and Xiu, D., 2011. “An Efficient Surrogate-Based Method for Computing Rare Failure Probability," Journal of Computational Physics. 230(24): 8683-8697.

Lunn, D., Spiegelhalter, D., Thomas, A., \& Best, N., 2009. The BUGS project: Evolution, critique and future directions. Statistics in medicine, 28 (25): 3049-3067.

Minerals Management Service, 2000. Risk Assessment of Temporarily Abandoned or Shut-in Wells. Report 99041, Contract No: 1435-01-99-RP-3995.

Nielsen, T.D., Jensen, F.V., 2009. Bayesian Networks and Decision Graphs. Springer Science \& Business Media.

NORSOK D-010, 2013. Well Integrity in Drilling and Well Operations. NORSOK Standard D010, revision 4. Standards Norway, Lysaker. <http://www.standard.no/pagefiles/1315/d010r3.pdf>.

Onisko, A., Druzdzel, M.J., Wasyluk, H., 2001. Learning Bayesian network parameters from small data sets: application of Noisy-OR gates. International Journal of Approximate Reasoning. 27, 165-182.

Ouyang, S. and Allen, E. 2017. Offshore well abandonment: challenges and approach with DNV GL guideline of risk-based abandonment. Offshore Engineering and Technology, 1(1): 7183.

Schobi, R., Sudret, B., and Marelli, S., 2016, "Rare Event Estimation Using Polynomial-Chaos Kriging”. ASCE-ASME Journal of Risk Uncertainty in Engineering Systems. Part A, (published ahead of print March 28, 2016).

Siu, N.O., and Kelly, D.L., 1998. Bayesian Parameter Estimation in Probabilistic Risk Assessment. Journal of Reliability Engineering System Safety. 62(1-2): 89-116.

Total (2013). <http://www.elgin.total.com/elgin/pressrelease.aspx?contentid=640> (accessed on July 20, 2018).

Woodyard, A.H. 1982. Risk analysis of well completion systems. Society of Petroleum Engineers, 9414: Journal of Petroleum Technology. 713-720.

Yan, Z., and Haimes, Y. Y., 2010. Cross-Classified Hierarchical Bayesian models for risk-based analysis of complex systems under sparse data. Journal of Reliability Engineering and System Safety. 95(7):764-776.

Yang, M., Khan, F., and Lye, L., 2013. "Precursor-Based Hierarchical Bayesian Approach for rare event frequency estimation: A Case of Oil Spill Accidents," Journal of Process Safety and Environmental Protection. 91(5): 333-342. 